\title{
Proceeding
}

9th INSHS International Christmas Sport Scientific Conference, 4-6 December 2014. International Network of Sport and Health

Science. Szombathely, Hungary

\section{Adaptative displays of body constitution in gravity cyclists}

\author{
DAMJAN SIRIŠKI $\triangleleft$, JAN NOVOTNÝ \\ Faculty of Sports Studies, Masaryk University, Czech Republic
}

\begin{abstract}
Siriški, D., \& Novotný, J. (2015). Adaptative displays of body constitution in gravity cyclists. J. Hum. Sport Exerc., 9(Proc1), pp.S212-S217.The objective of our study was to investigate somatotype, body constitution and motor skills of elite cyclists of technical gravity disciplines (freestyle MTB, biketrial) and downhill gravity disciplines (fourcross, downhill) and to characterize the impact of specific training process on body constitution and level of motor skills. Test group consisted of 30 riders (15 technical gravity disciplines, 15 downhill gravity disciplines). We used Heath-Carter method to define somatotype and Matiegka method to define body constitution of cyclists. Participants attended 2 motor skills tests focused on explosive leg strength and coordination (broad jump, twist jump).Downhill gravity cyclists proved significantly higher muscle mass (downhill disciplines $47.2 \%, \sigma=3.9 \%$; technical disciplines $44.3 \%, \sigma=$ $3.08 \% ; p=0.0564$ ) and higher value of mesomorph component (downhill disciplines 5.04, $\sigma=0.43$; technical disciplines 4.66, $\sigma=0.69 ; p=0.1103$ ). There were no significant differences in other anthropometric values. Downhill gravity cyclists proved statistically significant differences in broad jump (downhill disciplines $226.9 \mathrm{~cm}, \sigma=21.15 \mathrm{~cm}$; technical disciplines $210 \mathrm{~cm}, \sigma=15,17 \mathrm{~cm} ; p=0.042$ ). Technical gravity cyclists proved statistically significant differencies in twist jump (technical disciplines $547.7^{\circ}, \sigma=110.3^{\circ}$; downhill disciplines $441.5^{\circ}, \sigma=65.1^{\circ} ; p=0.0074$ ).Differences in somatotype, body constitution and motoric tests relate with characteristics of training and use of specific training methods. In this study high level performance athletes were tested, therefore it could be helpful for riders and coaches to increase the efficiency of the training process. Key words: MOTOR SKILLS, SOMATOTYPE, TRAINING PROCESS.
\end{abstract}

\footnotetext{
Corresponding author. Masaryk University, Žerotínovo nám. 617/9,601 77 Brno, Czech Republic

E-mail: 156111@mail.muni.cz

9th INSHS International Christmas Sport Scientific Conference, 4-6 December 2014. International Network of Sport and

Health Science. Szombathely, Hungary.

JOURNAL OF HUMAN SPORT \& EXERCISE ISSN 1988-5202

(c) Faculty of Education. University of Alicante

doi:10.14198/jhse.2015.10.Proc1.08
} 


\section{INTRODUCTION}

Gravity cycling disciplines are the youngest branch of cycling and although they are not far as popular as traditional cycling disciplines, they have been growing fast and are getting a lot of attention. After two decades of existence of these disciplines, scientific publications, which study impact of training on body composition of riders or describe training methods, started to come into existence.

Every year hundreds of newcomers get involved in the gravity cycling disciplines worldwide. Bigger base of riders is related with founding of new clubs and recruiting of new coaches and training experts. To keep the sport progressing, it is important to keep on improving the training methods and to apply knowledge of specific training process for each discipline.

The physique of an athlete is considered to be an important determinant of success in many sports, and in top level sport there would appear to be a tendency for individuals to gravitate towards the event to which they are anthropometrically best suited (Foley et al., 1989).

Factors of sport performance are clearly influenced by metabolic (Allemeier et al. 1994; Dawson et al. 1998) and neural factors (Casabona et al., 1990; Nummela et al., 1994), however, anthropometric factors also play an important role (Mann et al., 1984).

The aim of our thesis was to compare anthropometric characteristics of gravity cyclists. These information could help with talent scouting and to enhance training methods for coaches and athletes.

\section{METHODS}

30 male elite cyclists were studied in the investigation. The average age of cyclists was 18.9 years of age $(\sigma=2.3)$. Average weight of cyclists was $71.76 \mathrm{~kg}(\sigma=6.45)$ and average height was $178.6 \mathrm{~cm}(\sigma=5.56)$.

In our research we divided gravity disciplines into two groups. Downhill gravity disciplines (fourcross and downhill $\mathrm{mtb}$ ) and technical gravity disciplines (freestyle mtb and biketrial).

Each of the resulting groups contained a mixture of abilities. All anthropometric measures were taken by the same investigator.

We used Heath-Carter method (Heath et al., 1967) to define somatotype and Matiegka method (Matiegka, 1921) to define physique of cyclists. Participants attended 2 motor skills tests focused on explosive leg strength (broad jump - the jumper stands at a line marked on the ground with the feet slightly apart; the athlete takes off and lands using both feet; the measurement used is the longest of three tries) and coordination (twist jump - the jumper stands with a line marked on the ground in between his legs; the athlete takes off with rotation and lands with both feet).

Skinfold measurements were taken using a Somet caliper, the sites measured were tricep, bicep, subscapular, chest, abdominal, suprailiac, forearm, medial calf and thigh.

A Holtain sliding bone width caliper was used to assess the bi-epicondular breadths of the humerus and femur and the width of the ankle (across the lateral malleolus of the fibula and the medial malleolus of the tibia) and wrist. 
The biceps, calf, femur and forearm muscle girths were measured using a steel tape according to the procedure described by Heath and Carter (Heath et al., 1967). Height was measured to the nearest centimetre following a deep inspiration and weight was measured to the nearest half kilogram.

From the data obtained, ANTROPO1 software was used to calculate somatotype and physique rating for each athlete according to the methods described by Heath (Heath et al., 1967) and Matiegka (Matiegka, 1921). The data for the groups of cyclists were compared statistically using Mann-Whitney nonparametric test in STATISTICA software.

\section{RESULTS}

A comparison between the two groups revealed differences in somatotype and physique. The differences are summarized in Table 1 with the somatotypes presented diagrammatically in Figure 1.

The average somatotype for each of the groups was as follows - downhill disciplines endomorphy 2.4 ( $\sigma=$ $0.45)$, mesomorphy $5(\sigma=0.43)$, ectomorphy $2.9(\sigma=0.63)$; technical disciplines endomorphy $2.6(\sigma=$ $0.49)$, mesomorphy $4.7(\sigma=0.69)$, ectomorphy $3(\sigma=0.59)$.

Table1. Averages and deviations of somatotype and physique parameters

\begin{tabular}{cccccc}
\hline \multirow{2}{*}{ Variable } & \multicolumn{3}{c}{ Downhill } & \multicolumn{3}{c}{ Technical } & \multirow{2}{*}{$p$} \\
\cline { 2 - 5 } & $\mathrm{x}$ & $\sigma$ & $\mathrm{x}$ & $\sigma$ & 0.3611 \\
ENDO & 2.4 & 0.45 & 2.6 & 0.49 & 0.5067 \\
MESO & 5 & 0.43 & 4.7 & 0.69 & 0.1102 \\
ECTO & 2.9 & 0.63 & 3 & 0.59 & 0.5741 \\
Bone\% & 17.3 & 1.51 & 16.8 & 1.17 & 0.0563 \\
Muscle\% & 47.15 & 3.89 & 44.28 & 307 & 0.3833 \\
Fat\% & 13.8 & 1.91 & 13.32 & 1.95 & \\
\hline
\end{tabular}

Table 2. Somatotype and physique differences in groups demonstrated by Mann-Whitney nonparametric test

\begin{tabular}{cccccccc}
\hline Variable & $\begin{array}{c}\text { Total } \\
\text { Downh }\end{array}$ & Total Techn & $\mathrm{U}$ & $\mathrm{Z}$ & $p$-value & $\begin{array}{c}\text { Z- } \\
\text { adjust }\end{array}$ & $p$-value \\
\hline ENDO & 210.000 & 255.000 & 90.00 & -0.912 & 0.3615 & -0.9132 & 0.3611 \\
ECTO & 216.000 & 249.000 & 96.00 & -0.663 & 0.5069 & -0.6638 & 0.5067 \\
MESO & 271.500 & 193.500 & 73.50 & 1.596 & 0.1102 & 1.5972 & 0.1102 \\
Bone\% & 246.500 & 218.500 & 98.50 & 0.559 & 0.5755 & 0.5619 & 0.5741 \\
Muscle\% & 279.000 & 186.000 & 66.00 & 1.907 & 0.0563 & 1.9084 & 0.0563 \\
Fat\% & 254.000 & 211.000 & 91.00 & 0.871 & 0.3837 & 0.8717 & 0.3833 \\
\hline \multicolumn{7}{c}{ Mann-Whitney U test } \\
statistical significance $p<, 10000$ &
\end{tabular}

Analysis of the mesomorphy component showed the downhill disciplines group to be more mesomorphic than technical disciplines $(p=0.1)$. No significant difference was found in the ectomorphy and endomorphy rating. 


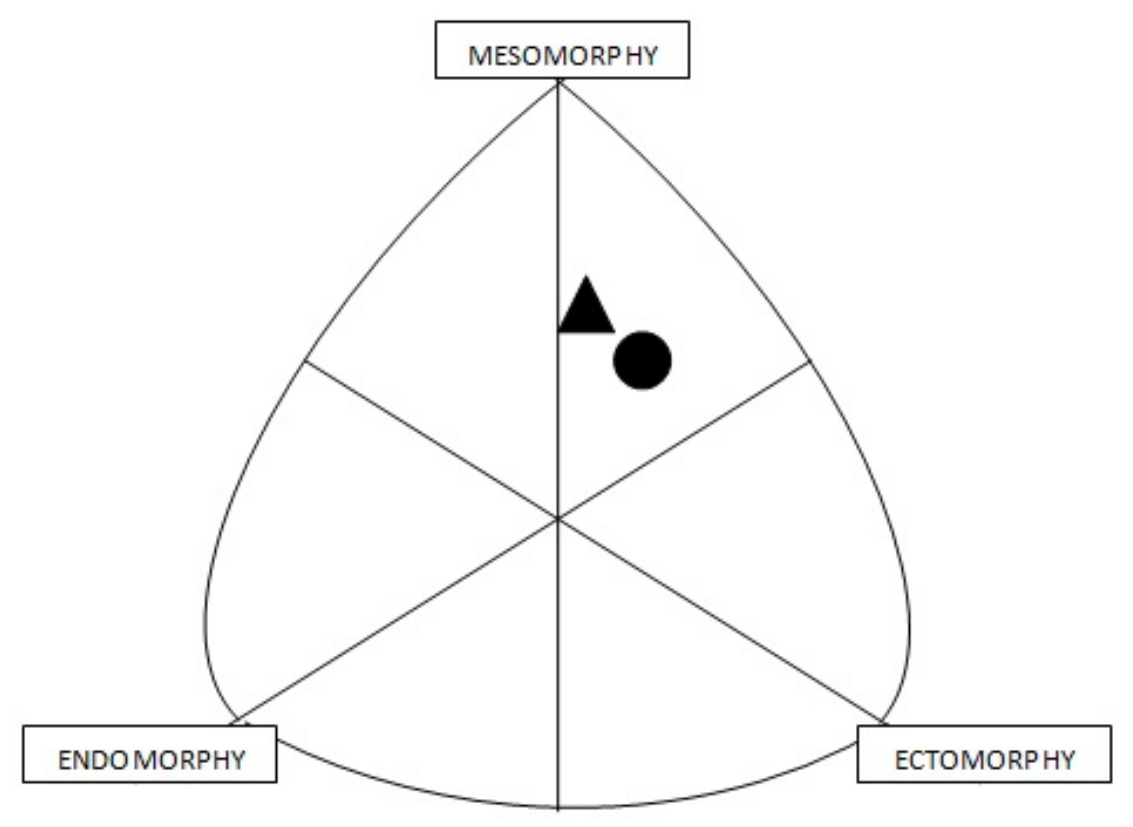

Figure 1. Average somatotypes of cyclists in present study:

$\Delta$ downhill gravity disciplines; technical gravity disciplines

Analysis of the physique ratings revealed difference in muscle mass component. Downhill disciplines group showed to have higher rating of muscle mass $(p=0.1)$. No significant differences were found between the groups in other physique components.

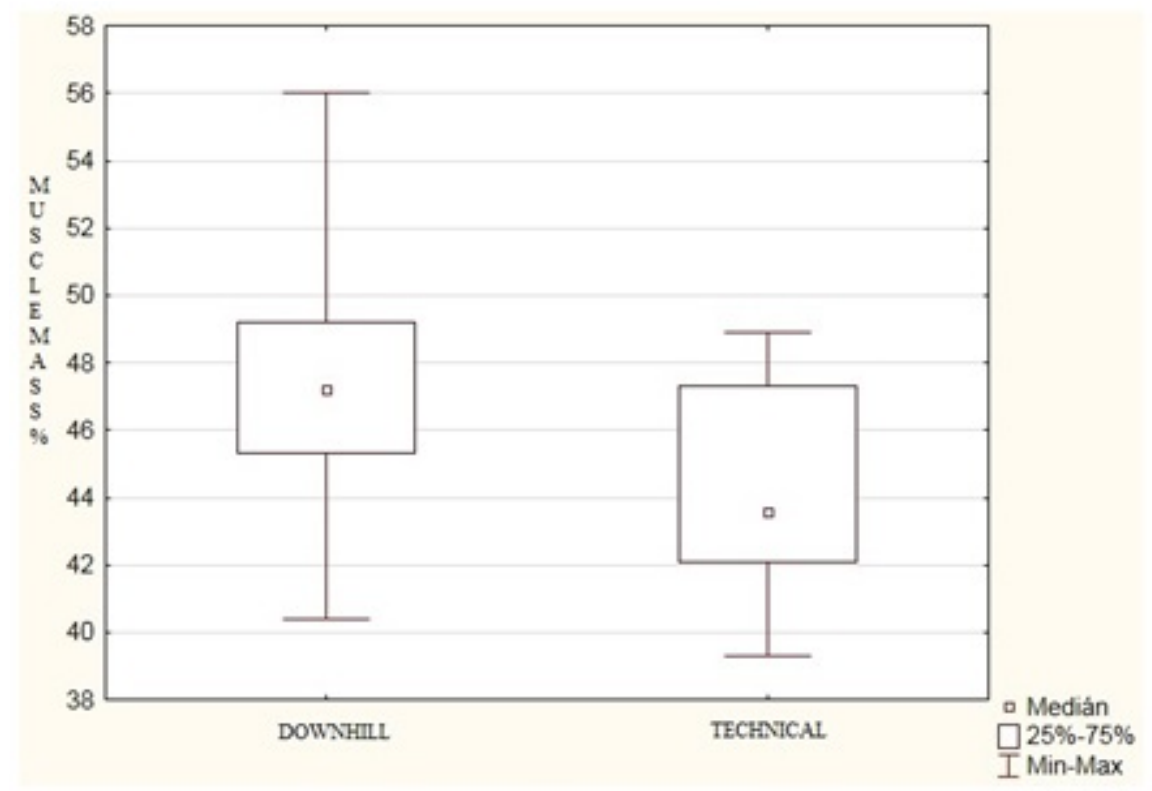

Figure 2. Display of differences in muscle mass between downhill and technical disciplines 
Table 3. Motor skills results differences in groups demonstrated by Mann-Whitney nonparametric test

\begin{tabular}{|c|c|c|c|c|c|c|c|}
\hline Variable & $\begin{array}{l}\text { Total } \\
\text { Downh }\end{array}$ & $\begin{array}{l}\text { Total } \\
\text { Techn }\end{array}$ & U & Z & $p$-value & Z-adjust & $p$-value \\
\hline Broad jump & 282.000 & 183.000 & 63.000 & 2.032 & 0.0421 & 2.033 & 0.0419 \\
\hline \multicolumn{8}{|c|}{$\begin{array}{c}\text { Mann-Whitney } \mathrm{U} \text { test } \\
\text { statistical significance } p<, 050000\end{array}$} \\
\hline Variable & $\begin{array}{l}\text { Total } \\
\text { Downh }\end{array}$ & $\begin{array}{l}\text { Total } \\
\text { Techn }\end{array}$ & U & Z & p-value & Z-adjust & $p$-value \\
\hline Rotation jump & 167.500 & 297.500 & 47.500 & -2.675 & 0.0074 & -2.676 & 0.0074 \\
\hline
\end{tabular}

A comparison between the two groups revealed significant differences in results of both motor skills tests. The average results of broad jump test was as follows; downhill disciplines $226.9 \mathrm{~cm}$, technical disciplines $210 \mathrm{~cm}$. Analysis of broad jump test showed the downhill disciplines group to have significantly higher rating of results of the test $(p=0.05)$. Analysis of rotation jump test showed the technical disciplines to have significantly higher rating of results of the test $(p=0.05)$.

\section{DISCUSSION}

The results supported suggestions that there was a high correlation between mesomorphy and body strength (White et al., 1978). The high mesomorphy of downhill disciplines riders might be expected, since strength is a major contributor of generating the power and obtaining a high rate of pedal revolutions (De Garay et al., 1989), which is an important factor in fourcross and downhill sport performance. The lower mesomorphy ratings in technical disciplines may relate to the relative tallness resulting in more ectomorphic physique.

Downhill disciplines group's significantly higher rating of broad jump results may relate to importance of explosive leg strength and ability of quicker acceleration as a major determinant of success in the disciplines. This suggestion may also be connected with higher rating of mesomorphy in downhill disciplines group.

Technical disciplines group's significantly higher rating of rotation jump results correlates with the long-term training process, as the athletes of these disciplines train to execute tricks which include rotating and spinning. Coordination and spatial orientation skills are determinant of successful sport performance in freestyle and biketrial.

\section{CONCLUSIONS}

Significant differencies were detected between the two groups of gravity cyclists. The downhill disciplines riders were more mesomorphic and had a higher rating of muscle mass component. The results in broad jump test revealed that downhill disciplines riders had higher rating in the test. Therefore it may be suggested that higher mesomorphy rating and higher muscle mass is a major contributor of generating the explosive power in legs which is a determinant of successful sport performance in downhill disciplines. The results in rotation jump test revealed that technical disciplines riders had higher rating in the test, which may relate with important role of coordination and spatial orientation skills in technical disciplines' sport performances. 
It may be suggested that each form of gravity cycling disciplines may require a different optimum physique and level of motor skills rather than a general cyclist's physique for all types of competition.

\section{REFERENCES}

1. Allemaier C.A., Fry A.C., Johnson P., Hikida R.S., Hagerman F.C., \& Staron R.S. (1994). Effects of sprint cycle training on human skeletal muscle. Journal of Applied Physiology, 77(5), pp.23852290.

2. Casabona A., Polizzi M.C., \& Perciavelle V. (1990). Differences in H-reflex between athletes trained for explosive contractions and non-trained subjects. European Journal of Applied Physiology and Occupational Physiology, 61(1), pp.26-32.

3. Dawson B., Fitzsimons M., Green S., Goodman C., Carey M., \& Cole K. (1998). Changes in performance, muscle metabolites, enzymes and fibre types after short sprint training. European Journal of Applied Physiology and Occupational Physiology, 78(2), pp.163-169.

4. Heath, B.H., \& Carter, J.E.L. (1967). A modified somatotype method. Am J Anthrop, 27(1), pp.5774.

5. Mann, R.V., Kotmel, J., Herman J., \& Schultz, C. (1984). Proceedings of the International Symposium of Biomechanics in Sports. Sports biomechanics. Kinematic trends in elite sprinters. California: Academic Publishers.

6. Matiegka, J. (1921). The testing of physical efficiency. American journal of physical anthropology, 4(3), pp.223-230.

7. Nummela A., Rusko H., \& Mero A. (1994). EMG activities and ground reaction forces during fatigued and nonfatigued sprinting. Scandinavian Journal of Sport Sciences 26, pp.605-609.

8. White, J.A., Quinn, G., Al-Dawalibi, M., \& Mulhall, J. (1978). A technical report submitted to the British Cycling Federation with special reference to the evaluation of the road squad's winter training programme. 